\title{
Metaevidence: what evidence there is on the results of the application of evidence?
}

\author{
José Luis Sandoval-Gutiérrez \\ Department of Pulmonology, Instituto Nacional de Enfermedades Respiratorias Ismael Cosío Villegas, Ciudad de México, Mexico
}

\begin{abstract}
The evidence-based medicine has enjoyed wide acceptance in the last two decades as the necessary tool for the adequate management of information, but it is necessary to reflect that exists after making an analysis of the written and possible implementation to the patient.
\end{abstract}

KEY WORDS: Evidence. Metaevidence. Clinical trial.

In 2012, Dr. Julio Mayol wrote on his Twitter the phrase that is the title of this manuscript ${ }^{1}$. The term "meta-evidence" is used in the science of law in the USA, but with regard to health sciences it is a term that has not been employed, and the most common one is meta-analysis? ${ }^{2}$.

For decades, evidence-based medicine ${ }^{3}$ has reigned in the clinical setting as the maximum ruler of decisions, but patient inclusion, exclusion of cases due to complexity and results being produced in a certain time, usually sooner than conventionally expected, have been increasingly questioned.

In the real-life hospital setting there are no exclusion criteria, patients arrive with multiple pathologies regardless of whether they meet the requirements of a protocol and, therefore, reading the most recent studies and trials showing the goodness of some approach or treatment is far from the above mentioned reality.

On one occasion, one doctor questioned whether the results in an article reporting a mortality decrease with an intervention would be due to the effectiveness of the strategy or because the patients who participated in the protocol were better taken care of.
When there is a study population, medical care and laboratory testing increase much higher than expected according to inertial or regular medical care in an institution; although this is necessary and desirable in an investigation, these conditions cannot be found in everyday life in a hospital setting.

Frustration is common in informed clinicians who, when reading about great advances in high academic impact journals, cannot replicate the reported results in their area of work, and seek to achieve the mortality rates of a given specialized center or the recovery time of a given hospital but, ultimately, "the human being ends up being hostage of his circumstances", as regards the approach to reported results and their applicability in their working area.

This situation is not exclusive of countries considered to be outside the industrialized nations' club, since in institutions of the latter there are also technological and human resources differences that hinder homologating the results at all levels of care. For example, mortality reported for a certain condition in a high specialty center in our country can be diametrically opposed to that in a secondary care center from
Gac Med Mex. 2017;153:827-828

Contents available at PubMed www.gacetamedicademexico.com 
a different region of the republic, and this can generate false and unfair comparisons.

The hospital certification culture of recent years, which emphasizes on following quality indicators seeking to homologate with standards reported in other countries, especially in those regarded as firstworld nations, causes physical and emotional burnout by not being able to match such level of demand, owing to a basic disproportion in terms of resources, which limits the results.

That what should be aspired to should be making a sensible reading of different reported works; as one teacher commented once: "just as you cannot believe everything you hear, you cannot believe everything you read".

Feasibility is what determines the implementation of promising results of some scientific work; in case they cannot be applied due to the existing situation, they point at future strategy.

\section{References}

1. Metaevidencia: ¿qué evidencia hay sobre los resultados de la aplicación de la evidencia?. Disponible en: https://twitter.com/juliomayol/status/256133078764888064 (consultado el 3 de junio de 2016).

2. Mueller, C.B. Meta-Evidence: Do We Need It, 25 Loy. L.A. L. Rev. 819 (1992). Disponible en: http://digitalcommons.Imu.edu/llr/vol25/iss3/12/ (consultado el 4 de junio de 2016).

3. Evidence-Based Medicine. http://ebm.bmj.com/(consultado el 5 de junio de 2016). 